\title{
Karakterisasi Sifat Agronomi Tanaman Padi Beras Merah Dihaploid Berpotensi Hasil Tinggi Diperoleh melalui Kultur Antera
}

\author{
Agronomic Characterization of Doubled Haploid Lines \\ of High Yielding Red Rice Obtained from Anther Culture
}

\author{
Mawaddah $^{1}$, Bambang Sapta Purwoko ${ }^{2 *}$, Iswari Saraswati Dewi ${ }^{3}$, dan Desta Wirnas ${ }^{2}$ \\ ${ }^{1}$ Program Studi Pemuliaan dan Bioteknologi Tanaman, Sekolah Pascasarjana, Institut Pertanian Bogor \\ ${ }^{2}$ Departemen Agronomi dan Hortikultura, Fakultas Pertanian, Institut Pertanian Bogor \\ (Bogor Agricultural University), Jl. Meranti, Kampus IPB Darmaga, Bogor 16680, Indonesia \\ ${ }^{3}$ Balai Besar Bioteknologi dan Sumber Daya Genetik Pertanian \\ Jl. Tentara Pelajar No. 3A, Cimanggu, Bogor, Indonesia
}

Diterima 30 Agustus 2017/Disetujui 26 Juni 2018

\begin{abstract}
Observation and identification of rice germplasm with advanced traits are important activities in the process of obtaining a variety of rice because every genotype will show unique characters. Genotype derived from breeding program as anther culture need to be characterized to identify the doubled haploid lines that are potential to be developed in red rice breeding. This research was aimed to obtain agronomic characters of doubled haploid lines of red rice. Materials used were 59 genotypes, i.e., 57 doubled haploid $\left(\mathrm{DH}_{0}\right)$ lines with red grain and 2 check varieties (Inpari 24 and Aek Sibundong) as control. The experiment used a randomized complete block design with three replications. The results exhibited there was agronomic variation among $\mathrm{DH}_{0}$ of red rice lines. Variance analysis showed that genotype affected most characters, except for grain dry weight per hill. Plant height, number of productive tiller, harvesting age, panicle length, number of grains per panicle, and number of filled grain per panicle can be used as a reference for effective selection to develop high productivity of red rice variety.
\end{abstract}

Keywords: advance lines, germplasm, heritability, homozygous

\section{ABSTRAK}

Pengamatan dan identifikasi plasma nutfah padi yang memiliki sifat-sifat unggul merupakan kegiatan penting dalam memperoleh varietas tanaman padi karena setiap genotipe akan menampilkan karakter yang unik. Genotipe yang diperoleh dari program pemuliaan seperti kultur antera perlu dikarakterisasi untuk mengidentifikasi galur-galur dihaploid yang berpotensi untuk dikembangkan dalam pemuliaan padi beras merah. Penelitian ini bertujuan untuk mendapatkan informasi tentang keragaman agronomi galur-galur dihaploid padi beras merah. Bahan yang digunakan adalah 59 genotipe yang terdiri atas 57 galur dihaploid $\left(\mathrm{DH}_{0}\right)$ tanaman padi terpilih dengan perikap biji berwarna merah dan 2 varietas beras merah ditanam sebagai pembanding yaitu Inpari 24 dan Aek Sibundong. Percobaan karakterisasi menggunakan rancangan kelompok lengkap teracak dengan tiga ulangan. Hasil penelitian menunjukkan bahwa karakter antar $D H_{0}$ padi beras merah bervariasi. Genotipe berpengaruh sangat nyata terhadap hampir semua karakter yang diamati, kecuali untuk peubah hasil gabah kering per rumpun. Karakter tinggi tanaman, umur panen, panjang malai, jumlah gabah per malai, dan jumlah gabah isi per malai dapat digunakan sebagai acuan seleksi yang efektif untuk memperoleh varietas padi beras merah unggul berproduksi tinggi.

Kata kunci: galur harapan, heritabilitas, homozigot, plasma nutfah

\section{PENDAHULUAN}

Beras merah adalah beras pecah kulit (tanpa penyosohan), yang lapisan kulit luar atau perikapnya

\footnotetext{
* Penulis untuk korespondensi. e-mail: bspurwoko@apps.ipb. ac.id
}

masih melekat pada endosperm. Lapisan kulit luar inilah mengandung antosianin yang tinggi, kaya akan vitamin B dan E, serta nilai gizi dan seratnya lebih tinggi dibandingkan dengan beras putih (Santika dan Rozakurniati 2010; Indrasari et al., 2010; Indrasari, 2011). Keunggulan akan kandungan gizi tersebut juga didukung dengan potensi ekonomi yang menguntungkan, sehingga peningkatan produktivitas padi 
beras merah menjadi penting karena dapat dimanfaatkan untuk menanggulangi berbagai permasalahan pangan, gizi, dan ekonomi terutama di Indonesia. Menurut Djoar et al. (2013) padi beras merah dapat menjadi sebuah peluang usaha karena produksi dan harga gabah tinggi, kondisi lahan cocok, merupakan makanan pokok dan memiliki potensi diversifikasi bahan olahan.

Sebagian besar tanaman padi beras merah dan hitam merupakan varietas lokal yang telah beradaptasi dengan cekaman biotik maupun abiotik wilayah tertentu (Sitaresmi et al., 2013). Oleh karena itu, peningkatan produktivitas perlu dilakukan melalui program pemuliaan. Salah satu caranya adalah melalui kultur antera.

Pemanfaatan tanaman dihaploid hasil kultur antera untuk pemuliaan dapat meningkatkan efisiensi proses seleksi, menghemat biaya, waktu, dan tenaga kerja karena galur murni dengan homosigositas tinggi dapat dihasilkan langsung pada generasi pertama (Dewi dan Purwoko, 2012). Populasi galur padi dihaploid (DH) yang dihasilkan dari kultur antera merupakan galur dengan konstitusi genetik homozigot heterogen, sehingga karakter agronomi antar galur dalam populasi DH mempunyai keragaman besar (Dewi et al., 2009). Galur-galur DH dapat digunakan sebagai sumber keragaman baru yang berpotensi sebagai bahan seleksi untuk perakitan varietas unggul padi beras merah.

Setiap varietas tanaman mempunyai sifat atau karakter yang berbeda. Pengamatan dan identifikasi plasma nutfah padi yang memiliki sifat-sifat unggul merupakan kegiatan penting dalam perbaikan varietas tanaman padi (Rusdiansyah dan Intara, 2015). Kegiatan karakterisasi bertujuan mengetahui sifat-sifat atau karakter agronomi dan morfologi tanaman.

Penelitian Dewi et al. (2009) telah mengidentifikasi beberapa karakter morfologi baru pada populasi DH yang diamati, yang sebelumnya tidak ada pada kedua tetua pembentuknya. Hasil tersebut menunjukkan DH hasil kultur antera mempunyai peluang dalam memperoleh karakterkarakter baru yang unggul.

Tanaman yang dikarakterisasi pada penelitian ini merupakan hasil kultur antera dari persilangan beberapa plasma nutfah padi beras merah dan galur-galur harapan yang sudah memiliki sifat agronomi yang baik. Penelitian ini bertujuan untuk mendapatkan galur-galur DH dengan keragaan agronomi yang beragam sebagai bahan seleksi dan memperoleh galur-galur beras merah yang memiliki potensi hasil tinggi.

\section{BAHAN DAN METODE}

Percobaan dilaksanakan di Rumah Kaca Cikabayan Bawah, Departemen Agronomi dan Hortikultura, Fakultas Pertanian, Institut Pertanian Bogor, Dramaga, Bogor, Indonesia dan dimulai dari bulan Juli sampai dengan Desember 2016. Bahan yang digunakan adalah 59 genotipe yang terdiri atas $57 \mathrm{DH}_{0}$ tanaman padi terpilih dengan perikap biji berwarna merah dan 2 varietas beras merah ditanam sebagai pembanding yaitu Inpari 24 dan
Aek Sibundong (Gambar 1). Bahan tanam diperoleh dari Balai Besar Penelitian dan Pengembangan Bioteknologi dan Sumber Daya Genetik Pertanian, Bogor, Indonesia. Rancangan percobaan yang digunakan yaitu rancangan kelompok lengkap teracak dengan tiga ulangan, sehingga terdapat 177 unit percobaan. Uji lanjut Dunnett pada taraf uji 5\% dilakukan jika uji $\mathrm{F}$ nyata pada peubah yang diamati.

Sebanyak 59 genotipe dikecambahkan pada cawan petri selama 3 hari, kemudian ditanam pada bak persemaian yang berisi lumpur. Setelah tanaman berumur 21 hari, bibit dipindahkan sebanyak 1 tanaman per ember dengan media tanah sawah sebagai unit percobaan dan ditempatkan di rumah kaca. Perawatan tanaman hingga panen meliputi penyiraman dengan mengkondisikan tanah dalam keadaan macak-macak, penyiangan gulma, pemupukan dengan $200 \mathrm{~kg} \mathrm{ha}^{-1}$ urea, $100 \mathrm{~kg} \mathrm{ha}^{-1}$ SP36, $100 \mathrm{~kg} \mathrm{ha}^{-1} \mathrm{KCl}$, dan pengendalian hama wereng dengan penyemprotan insektisida yang mengandung bahan aktif Imidakloprid $5 \%$. Pemanenan dilakukan pada malai yang telah $80 \%$ menguning.

Karakterisasi agronomi $\mathrm{DH}_{0}$ dilakukan terhadap karakter tinggi tanaman $(\mathrm{cm})$ diukur pada usia 12 minggu setelah tanam, jumlah anakan produktif (batang per rumpun) dihitung pada usia 12 minggu setelah tanam, umur panen (hari setelah semai) dihitung jika 80\% malai siap dipanen, panjang malai $(\mathrm{cm})$ diukur dari leher malai sampai ujung malai, jumlah gabah per malai (butir), jumlah gabah isi per malai (butir), jumlah gabah hampa per malai, bobot gabah 100 butir (g), dan hasil gabah kering per rumpun (g) dihitung dari bobot gabah kering bernas yang berasal dari satu rumpun. Analisis selanjutnya yaitu menduga nilai heritabilitas arti luas dan pengelompokan nilai heritabilitas

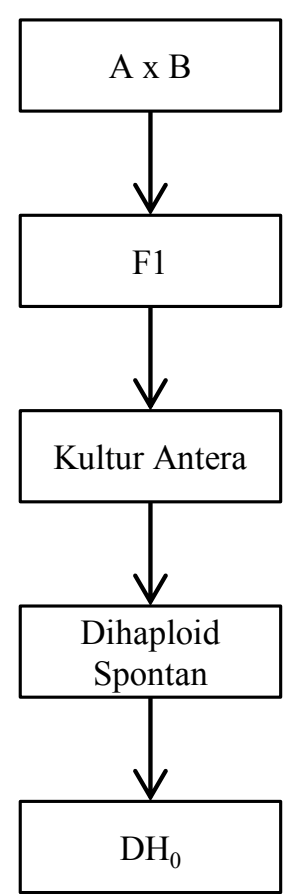

Gambar 1. Tahapan memperoleh benih $\mathrm{DH}_{0}$ pada pemuliaan tanaman padi 
menurut Stanfield (1983), koefisien keragaman genotipik (KKG) diduga dengan akar kuadrat dari ragam genotipe dibagi rataan umum karakter dikalikan 100\%.

\section{HASIL DAN PEMBAHASAN}

\section{Keragaman Agronomi Galur-galur Dihaploid}

Analisis ragam mengindikasikan bahwa terdapat keragaman antar $\mathrm{DH}_{0}$ padi beras merah yang diuji pada hampir semua karakter yang diamati yaitu karakter tinggi tanaman, jumlah anakan produktif, umur panen, panjang malai, jumlah gabah per malai, jumlah gabah isi per malai, jumlah gabah hampa per malai, dan bobot 100 butir, kecuali untuk karakter hasil gabah kering per rumpun (Tabel 1).

Tinggi tanaman $\mathrm{DH}_{0}$ beras merah berkisar antara 99.0$138.0 \mathrm{~cm}$. Terdapat dua galur dengan rerata tinggi tanaman nyata lebih pendek dibanding Inpari 24 yaitu MW5-5-1-3 dan MW4-40-1-5 (Tabel 2). Klasifikasi tinggi tanaman menurut Silitonga et al. (2003) terbagi ke dalam tiga kelas yaitu pendek $(<110 \mathrm{~cm})$, sedang $(110-130 \mathrm{~cm})$, dan tinggi $(>$ $130 \mathrm{~cm}$ ). Berdasarkan klasifikasi tersebut, terdapat 6 galur memiliki tinggi tanaman tergolong pendek, 43 galur dan kedua pembanding tergolong sedang, dan 8 galur tergolong tinggi. Menurut Dewi et al. (2009) umumnya petani kurang menyenangi varietas yang berpostur tinggi karena peka rebah, sedangkan varietas berpostur terlalu pendek $(<80$ $\mathrm{cm}$ ) menyulitkan ketika panen, sehingga seleksi untuk karakter tinggi tanaman pada pemuliaan padi umumnya tidak mengarah kepada postur tanaman yang tergolong tinggi.

Jumlah anakan produktif per rumpun $\mathrm{DH}_{0}$ beras merah berkisar antara 11.7-31.0 batang per rumpun (Tabel 2). Jumlah anakan dibedakan dalam lima kelompok yaitu sangat banyak $(>25)$, banyak (20-25), sedang (10-19), sedikit (5-9), dan sangat sedikit $(<5)$ (Silitonga et al., 2003). Berdasarkan pengelompokan tersebut, terdapat 15 galur dengan jumlah anakan produktif per rumpun tergolong sangat banyak, 25 galur tergolong banyak, 17 galur dan kedua pembanding tergolong sedang. Hasil pengelompokan tersebut mengindikasikan bahwa sebagian besar $\mathrm{DH}_{0}$ pada penelitian ini memiliki jumlah anakan produktif lebih banyak dari pembanding.

Umur panen $\mathrm{DH}_{0}$ beras merah berkisar antara 104.0128.5 hari. Terdapat satu galur dengan rerata umur panen nyata lebih genjah dibanding kedua varietas Aek Sibundong dan Inpari 24 yaitu MW4-62-2-2. Terdapat pula tujuh galur dengan rerata umur panen nyata lebih genjah dibanding Aek Sibundong yaitu MW5-5-1-3, MW5-19-1-2, MW312-1-2, MW4-40-1-5, MW4-6-1-3, MW5-6-1-1, MW358-1-2 (Tabel 2). Menurut klasifikasi umur panen tanaman padi terdapat 5 kelompok yaitu, ultra genjah (<90 HSS), sangat genjah (90-104 HSS), genjah (105-124 HSS), sedang (125-150 HSS), dan dalam (> 150 HSS) (BB Padi, 2010). Berdasarkan klarifikasi tersebut, sebagian besar $\mathrm{DH}_{0}$ yang diuji dan kedua pembanding tergolong memiliki umur panen genjah.

Panjang malai $\mathrm{DH}_{0}$ beras merah berkisar antara 18.4$30.7 \mathrm{~cm}$. Terdapat 27 galur dengan rerata panjang malai nyata lebih pendek dibanding Inpari 24, panjang malai galurgalur tersebut berkisar antara 18.4-21.7 cm. Namun, tidak terdapat galur dengan rerata malai lebih panjang dibanding kedua varietas pembanding (Tabel 2).

Jumlah gabah total per malai $\mathrm{DH}_{0}$ beras merah berkisar antara 81.9-242.8 butir. Terdapat empat galur dengan rerata jumlah gabah total per malai nyata lebih banyak dibanding Aek Sibundong yaitu MW2-7-1-2, MW2-7-1-3, MW2-2-22, dan MW3-9-3-1, sedangkan 47 galur lainnya memiliki jumlah gabah total per malai yang tidak berbeda dengan kedua varietas pembanding (Tabel 2).

Jumlah gabah isi per malai $\mathrm{DH}_{0}$ beras merah berkisar antara 59.3-177.0 butir. Hasil penelitian menunjukkan terdapat lima galur dengan rerata jumlah gabah isi per malai nyata lebih banyak dibanding Aek Sibundong, yaitu MW-39-3-1, MW2-2-2-1, MW3-9-2-1, MW2-7-1-2, dan MW2-71-1 (Tabel 2). Galur-galur tersebut memiliki jumlah gabah isi per malai lebih dari 160 butir, yang memenuhi kriteria dalam pengembangan padi ideal menurut Zhengjin et al. (2005). Tidak terdapat perbedaan jumlah gabah isi per malai antara 52 galur lainnya dengan kedua varietas pembanding Aek Sibundong dan Inpari 24. Jumlah gabah isi mendukung potensi hasil padi, sehingga semakin tinggi fertilitas malai

Tabel 1. Analisis ragam karakter agronomi $\mathrm{DH}_{0}$ padi beras merah di rumah kaca Cikabayan

\begin{tabular}{lcc}
\hline Karakter & Genotipe & Koefisien keragaman (\%) \\
\hline Tinggi tanaman & $198.5^{* *}$ & 6.7 \\
Jumlah anakan produktif\# & $0.1^{* *}$ & 9.1 \\
Umur panen & $64.6^{* *}$ & 2.8 \\
Panjang malai & $23.0^{* *}$ & 8.1 \\
Jumlah gabah total per malai\# & $0.2^{* *}$ & 6.8 \\
Jumlah gabah isi per malai\# & $0.2^{* *}$ & 8.7 \\
Jumlah gabah hampa per malai\# & $0.2^{* *}$ & 13.3 \\
Bobot 100 butir & $7.9^{* *}$ & 11.6 \\
Hasil gabah kering per rumpun\# & 0.2 & 17.7 \\
\hline
\end{tabular}

Keterangan: tanda $* *=$ berpengaruh sangat nyata pada taraf $\alpha=5 \%$, tanda ${ }^{\#}=$ data ditransformasi menggunakan $\sqrt[1 / 4]{x}$ 
yang ditunjukkan oleh persentase gabah isi akan lebih berpeluang memberikan hasil yang tinggi (Hairmansis et al., 2010).

Jumlah gabah hampa per malai $\mathrm{DH}_{0}$ beras merah berkisar antara 12.0-92.4 butir. Sebagian besar $\mathrm{DH}_{0}$ yang diuji memiliki jumlah gabah hampa per malai lebih sedikit dibandingkan kedua varietas pembanding Aek Sibundong dan Inpari 24, hanya $4 \mathrm{DH}_{0}$ yang memiliki jumlah gabah hampa lebih banyak dari pembanding (Tabel 2).
Karakter bobot 100 butir gabah bernas pada $\mathrm{DH}_{0}$ beras merah berkisar antara antara 1.5-2.3 gram. Terdapat 10 galur dengan rerata bobot 100 butir gabah bernas nyata lebih ringan dibanding Aek Sibundong. Hasil penelitian menunjukkan bobot 100 butir paling berat dicapai oleh Aek Sibundong. Namun 47 galur lainnya tidak berbeda dengan kedua varietas pembanding (Tabel 2).

Hasil gabah kering per rumpun pada $\mathrm{DH}_{0}$ beras merah berkisar antara 6.4-51.8 g. Terdapat 25 galur dengan hasil

Tabel 2. Keragaan agronomi $57 \mathrm{DH}_{0}$ padi beras merah hasil kultur antera

\begin{tabular}{|c|c|c|c|c|c|c|c|c|c|}
\hline Genotipe & $\begin{array}{c}\mathrm{TT} \\
(\mathrm{cm})\end{array}$ & JAP & $\begin{array}{l}\text { UPAN } \\
\text { (hari) }\end{array}$ & $\mathrm{PM}(\mathrm{cm})$ & JGM & JGIM & JGHM & $\begin{array}{c}\text { B100 } \\
(\mathrm{g})\end{array}$ & $\begin{array}{l}\text { HGKR } \\
(\mathrm{g})\end{array}$ \\
\hline Aek Sibdng & 119.7 & 17.7 & 120.3 & 27.1 & 131.2 & 79.1 & 52.1 & 2.3 & 19.0 \\
\hline Inpari 24 & 126.3 & 17.7 & 115.3 & 26.7 & 177.4 & 132.2 & 45.2 & 2.0 & 26.5 \\
\hline MW2-2-1-1 & 116.3 & 17.7 & $126.7^{++}$ & 27.2 & 171.3 & 128.7 & 42.7 & 1.7 & 24.8 \\
\hline MW2-2-2-1 & 122.3 & 21.5 & $128.5^{++}$ & 28.3 & 204.5 & $173.0^{+}$ & 31.5 & 1.9 & 47.1 \\
\hline MW2-2-2-2 & 129.3 & 19.3 & $124.3^{++}$ & 29.2 & $211.2^{+}$ & 155.7 & 55.6 & $1.6^{\#}$ & 32.6 \\
\hline MW2-7-1-1 & 130.0 & 18.7 & $125.7^{++}$ & 28.3 & 191.7 & $162.3^{+}$ & 29.3 & 2.0 & 33.7 \\
\hline MW2-7-1-2 & 131.7 & 20.0 & 123.0 & 30.7 & $242.8^{+}$ & $165.9^{+}$ & 76.9 & 2.0 & 40.9 \\
\hline MW2-7-1-3 & 128.0 & 15.7 & 119.3 & 29.8 & $226.3^{+}$ & 149.0 & 77.3 & 1.9 & 25.2 \\
\hline MW3-12-1-2 & 121.7 & 30.0 & $110.7^{\#}$ & $21.6^{\# \#}$ & 116.2 & 75.1 & 41.1 & 1.8 & 21.5 \\
\hline MW3-13-1-1 & 117.7 & 28.3 & 120.7 & $18.9^{\# \#}$ & $91.0^{\# \#}$ & 60.8 & 30.2 & 1.8 & 17.3 \\
\hline MW3-13-1-2 & 114.0 & 20.7 & 121.7 & $18.9^{\# \#}$ & $95.2^{\# \#}$ & 67.0 & 28.2 & 1.9 & 6.4 \\
\hline MW3-13-1-3 & 122.7 & 31.0 & 121.0 & $20.5^{\# \#}$ & 103.6 & 76.8 & 26.8 & 1.9 & 26.0 \\
\hline MW3-13-1-4 & 127.7 & 25.3 & 119.3 & $20.9^{\# \#}$ & 123.2 & 88.2 & 35.0 & 2.0 & 24.0 \\
\hline MW3-19-1-2 & 129.7 & 23.7 & 115.3 & $21.7^{\# \#}$ & 122.0 & 100.3 & 21.7 & 2.1 & 30.0 \\
\hline MW3-24-1-1 & 125.3 & 22.7 & 116.7 & $20.2^{\# \#}$ & 114.9 & 96.2 & 18.7 & 2.0 & 26.3 \\
\hline MW3-24-1-2 & 107.0 & 24.5 & $111.0^{\#}$ & $21.0^{\# \#}$ & 105.3 & 65.2 & 40.2 & $1.5^{\#}$ & 10.9 \\
\hline MW3-24-1-3 & 123.8 & 22.7 & 113.3 & $21.3^{\# \#}$ & 119.0 & 93.4 & 25.6 & 1.8 & 24.9 \\
\hline MW3-24-1-4 & 114.3 & 26.5 & 115.0 & $19.5^{\# \#}$ & 97.7 & 79.3 & 18.3 & 1.8 & 27.1 \\
\hline MW3-24-2-5 & 112.7 & 22.0 & 115.3 & $18.4^{\# \#}$ & $81.9^{\# \#}$ & 66.2 & 15.7 & 1.9 & 18.3 \\
\hline MW3-24-2-6 & 118.0 & 28.0 & $111.5^{\#}$ & 21.9 & 127.7 & 82.7 & 45.0 & $1.6^{\#}$ & 20.9 \\
\hline MW3-32-2-4 & 126.7 & 25.0 & 113.3 & $21.4^{\# \#}$ & 113.0 & 85.2 & 27.8 & 1.8 & 21.8 \\
\hline MW3-58-1-1 & 129.3 & 24.0 & 116.3 & $21.6^{\# \#}$ & 127.3 & 111.4 & 15.9 & 2.1 & 35.1 \\
\hline MW3-58-1-2 & 136.7 & 30.7 & $111.0^{\#}$ & 22.8 & 141.2 & 123.0 & 18.2 & 2.1 & 43.8 \\
\hline MW3-58-1-3 & 127.8 & 31.0 & 113.3 & 22.8 & 143.7 & 114.3 & 29.3 & 2.0 & 39.0 \\
\hline MW3-58-2-1 & 128.3 & 30.3 & 112.3 & 22.6 & 127.7 & 112.9 & 14.8 & 2.0 & 43.6 \\
\hline MW3-58-2-5 & 128.3 & 24.3 & 114.0 & $20.9^{\# \#}$ & 127.7 & 107.6 & 20.1 & 1.8 & 25.2 \\
\hline MW3-9-2-1 & 134.7 & 18.0 & 114.0 & 24.6 & 201.1 & $167.3^{+}$ & 33.8 & 2.0 & 42.9 \\
\hline MW3-9-3-1 & 134.0 & 20.7 & 115.0 & 25.2 & $209.6^{+}$ & $177.0^{+}$ & 32.6 & 1.9 & 45.6 \\
\hline MW4-11-1-1 & 133.7 & 24.7 & 113.3 & $22.2^{\#}$ & 118.2 & 97.4 & 20.8 & 2.2 & 35.0 \\
\hline MW4-11-1-3 & 128.7 & 26.7 & 113.7 & $20.9^{\# \#}$ & 107.0 & 88.0 & 19.0 & 2.1 & 27.6 \\
\hline MW4-11-2-1 & 127.3 & 22.0 & 114.0 & $20.9^{\# \#}$ & 110.6 & 90.4 & 20.1 & 2.1 & 29.8 \\
\hline MW4-11-2-2 & 123.7 & 27.0 & 112.0 & $21.1^{\# \#}$ & 111.7 & 89.7 & 22.0 & 1.8 & 23.9 \\
\hline MW4-11-2-3 & 119.3 & 230 & 113.7 & $19.3^{\# \#}$ & $97.0^{\# \#}$ & 69.1 & 27.9 & 1.8 & 18.3 \\
\hline MW4-11-2-5 & 123.3 & 24.7 & 112.7 & $21.0^{\# \#}$ & 112.1 & 95.9 & 16.2 & 2.1 & 31.5 \\
\hline MW4-17-1-1 & 111.0 & 20.0 & 115.5 & $18.5^{\# \#}$ & 99.2 & 59.3 & 39.8 & 1.7 & 18.9 \\
\hline
\end{tabular}


Tabel 2. Keragaan agronomi $57 \mathrm{DH}_{0}$ padi beras merah hasil kultur antera (lanjutan)

\begin{tabular}{|c|c|c|c|c|c|c|c|c|c|}
\hline Genotipe & $\begin{array}{c}\mathrm{TT} \\
(\mathrm{cm})\end{array}$ & JAP & $\begin{array}{l}\text { UPAN } \\
\text { (hari) }\end{array}$ & $\mathrm{PM}(\mathrm{cm})$ & JGM & JGIM & JGHM & $\begin{array}{c}\text { B100 } \\
(\mathrm{g})\end{array}$ & $\begin{array}{c}\text { HGKR } \\
(\mathrm{g})\end{array}$ \\
\hline MW4-19-1-1 & 123.3 & 17.5 & 113.5 & 22.3 & 125.8 & 95.7 & 30.2 & 1.9 & 28.1 \\
\hline MW4-2-1-1 & 127.3 & 17.3 & 117.7 & 23.2 & 136.0 & 99.3 & 36.7 & 1.8 & 21.8 \\
\hline MW4-2-1-2 & 123.7 & 23.3 & 118.3 & 24.3 & 161.8 & 127.1 & 34.7 & 1.7 & 29.4 \\
\hline MW4-2-2-1 & 132.3 & 26.7 & 118.7 & 26.7 & 181.1 & 138.9 & 42.2 & 1.9 & 35.2 \\
\hline MW4-40-1-5 & $99.0^{\# \#}$ & 14.7 & $110.7^{-}$ & 22.7 & 122.1 & 79.6 & 42.6 & 1.9 & 13.4 \\
\hline MW4-46-1-1 & 111.0 & 17.5 & $124.5^{++}$ & 23.8 & 122.0 & 110.0 & 12.0 & 1.7 & 23.0 \\
\hline MW4-46-1-2 & 118.3 & 12.0 & $128.3^{++}$ & 22.3 & 116.4 & 99.7 & 26.1 & $1.7^{\#}$ & 20.0 \\
\hline MW4-53-1-1 & 128.0 & 23.5 & 115.0 & $21.1^{\# \#}$ & 125.2 & 84.5 & 40.7 & 1.8 & 21.3 \\
\hline MW4-53-1-2 & 122.0 & 18.3 & 113.7 & $19.5^{\# \#}$ & $94.7^{\# \#}$ & 68.7 & 26.0 & $1.7^{\#}$ & 19.2 \\
\hline MW4-6-1-1 & 129.7 & 16.0 & 120.7 & $20.9^{\# \#}$ & 122.2 & 108.9 & 19.1 & 1.8 & 28.6 \\
\hline MW4-6-1-2 & 129.7 & 22.3 & 120.0 & 23.8 & 166.3 & 117.7 & 48.7 & 1.8 & 27.4 \\
\hline MW4-6-1-3 & 138.0 & 26.7 & $111.7^{\#}$ & 23.9 & 160.8 & 141.0 & 19.8 & 2.1 & 51.8 \\
\hline MW4-62-2-1 & 132.3 & 25.7 & 114.0 & 22.2 & 139.8 & 113.9 & 25.9 & 1.9 & 39.1 \\
\hline MW4-62-2-2 & 123.7 & 21.5 & $104.0^{\# \#}$ & 22.3 & 115.8 & 77.5 & 38.3 & 1.8 & 18.1 \\
\hline MW5-19-1-2 & 107.3 & 22.3 & $110.3^{\#}$ & 22.9 & 117.8 & 103.3 & 14.4 & $1.6^{\#}$ & 21.7 \\
\hline MW5-5-1-3 & $104.0^{\# \#}$ & 19.7 & $110.3^{\#}$ & 23.9 & 139.0 & 113.2 & 25.8 & 2.1 & 30.2 \\
\hline MW5-5-2-1 & 125.3 & 12.7 & 115.0 & $21.6^{\# \#}$ & 118.0 & 99.3 & 18.7 & 1.7 & 14.5 \\
\hline MW5-6-1-1 & 122.3 & 21.3 & $111.7^{\#}$ & 22.7 & 148.8 & 120.0 & 28.8 & $1.7^{\#}$ & 26.1 \\
\hline MW5-6-1-2 & 119.3 & 16.7 & 113.0 & 23.2 & 134.8 & 105.3 & 29.4 & $1.5^{\#}$ & 13.6 \\
\hline MW5-72-1-1 & 117.3 & 20.5 & 113.5 & 23.5 & 155.2 & 142.2 & 13.0 & 1.9 & 41.0 \\
\hline MW6-32-1-1 & 112.7 & 11.7 & 119.3 & $21.7^{\# \#}$ & 199.1 & 106.7 & 92.4 & 1.7 & 10.6 \\
\hline MW6-70-1-6 & 119.3 & 29.0 & 113.7 & $21.1^{\# \#}$ & 108.3 & 74.3 & 34.0 & $1.6^{\#}$ & 17.3 \\
\hline MW6-70-2-2 & 106.7 & 17.5 & 116.0 & $19.3^{\# \#}$ & $86.7^{\# \#}$ & 64.0 & 22.7 & 1.9 & 13.1 \\
\hline MW6-8-1-1 & 106.3 & 24.7 & 115.7 & 23.2 & 139.6 & 94.6 & 45.0 & $1.7^{\#}$ & 22.0 \\
\hline
\end{tabular}

Keterangan: MW2 = Leukat Itam/IR 85627-46-1-2-3, MW3 = Malang/WI-44, MW4 = Malang/IR 85627-46-1-2-3, MW5 = Purworejo/ WI-44, MW6 = Purworejo/IR 85627-46-1-2-3, TT = tinggi tanaman, JAP = jumlah anakan produktif, UPAN = umur panen, $\mathrm{PM}=$ panjang malai, JGM = jumlah gabah per malai, JGIM = jumlah gabah isi per malai, JGHM = jumlah gabah hampa per malai, B100 = Bobot 100 butir, HGKR = hasil gabah kering per rumpun, ${ }^{+}$rata-rata genotipe lebih besar dibandingkan Aek Sibundong, ${ }^{++}$rata-rata genotipe lebih besar dibandingkan Inpari $24,{ }^{+++}$rata-rata genotipe lebih besar dibandingkan Aek Sibundong dan Inpari 24, "rata-rata Aek Sibundong lebih besar dibandingkan genotipe, "\#rata-rata Inpari 24 lebih besar dibandingkan genotipe

gabah kering per rumpun lebih berat dibanding Inpari 24, hasil tersebut berkisar antara 27.1-51.8 g. Terdapat pula 19 galur dengan hasil gabah kering per rumpun lebih berat dibanding Aek Sibundong yang beratnya berkisar antara 19.2-51.8 g (Tabel 2). Galur $\mathrm{DH}_{0}$ dengan bobot per rumpun terberat dicapai oleh galur MW4-6-1-3.

Tingginya hasil gabah kering per rumpun merupakan gabungan dari sejumlah karakter komponen hasil. Sebagai contoh galur MW4-6-1-3 merupakan galur dengan hasil gabah kering per rumpun paling berat diantara $57 \mathrm{DH}_{0}$ beras merah yang diuji dan kedua pembanding. Hasil tersebut didukung pula dengan jumlah anakan produktif yang tergolong sangat banyak, serta karakter panjang malai, jumlah gabah per malai, jumlah gabah isi, jumlah gabah hampa, serta bobot 100 butir yang tidak berbeda dari kedua pembanding. Persentase gabah bernas MW4-6-1-3 mencapai $83.7 \%$ dengan jumlah gabah isi tergolong tinggi dan jumlah gabah hampa tergolong rendah.

Terdapat keragaman karakter agronomi dan daya hasil di antara galur-galur yang dihasilkan dari kultur antera (Diptaningsari, 2013; Purbokurniawan et al., 2014). Galurgalur DH yang dihasilkan melalui kultur antera mempunyai keragaman yang layak dijadikan sebagai materi seleksi (Mishra et al., 2015). Hasil karakterisasi penelitian ini merupakan hasil pengamatan pada tanaman yang ditanam di rumah kaca dan tanaman diperlakukan secara khusus tidak dikondisikan dengan jarak tanam komersil, sehingga pengujian di lahan sawah masih perlu dilakukan untuk mengkonfirmasi potensi karakter-karakter agronomi yang terdapat pada $\mathrm{DH}_{0}$ padi beras merah yang diuji.

Perubahan karakter hasil suatu genotipe yang stabil tidak akan dipengaruhi oleh lingkungan, penelitian Dewi 
et al. (2015) menunjukkan terdapat mutan DH tetap dapat berproduksi tinggi meskipun indeks lingkungan untuk karakter hasilnya tinggi. Galur-galur DH pada penelitian sebelumnya juga terindikasi stabil dan memiliki daya adaptasi khusus pada lingkungan tercekam kekeringan (Aryana, 2009) dan tercekam Alumunium (Herawati et al., 2010).

\section{Pendugaan Komponen Ragam dan Heritabilitas}

Hasil penelitian menunjukkan sebagian besar karakter memiliki nilai heritabilitas yang tinggi (Tabel 3). Nilai heritabilitas yang tinggi dari karakter-karakter yang diamati mengindikasikan bahwa seleksi dapat diterapkan secara efisien pada karakter tersebut (Selvaraj et al., 2011; Mohamed et al., 2012; Kristamtini et al., 2016). Terdapat pula beberapa karakter tergolong dalam heritabilitas kriteria sedang yaitu jumlah anakan produktif, jumlah gabah hampa per malai, dan bobot 100 butir. Karakter dengan heritabilitas kriteria rendah hanya terdapat pada hasil gabah kering per rumpun (Tabel 3). Karakter yang mempunyai nilai duga heritabilitas tinggi menunjukan bahwa pengaruh faktor genetik lebih besar dibandingkan faktor lingkungan (Selvaraj et al., 2011; Mohamed et al., 2012).

Nilai heritabilitas tertinggi terdapat pada karakter panjang malai, diikuti umur panen, dan jumlah gabah per malai (Tabel 3). Sejalan dengan penelitian Herawati (2009) perbaikan jumlah gabah per malai dan jumlah gabah isi per malai lebih efektif karena memiliki nilai heritabilitas yang tinggi dan keragaman genetik yang luas.

Karakter seleksi harus memiliki keragaman dan heritabilitas yang tinggi, agar diperoleh target kemajuan seleksi. Seleksi akan memberikan respon yang optimal bila didukung oleh komponen pertumbuhan dan komponen hasil yang berkorelasi kuat dengan daya hasil (Handayani dan Hidayat, 2012; Limbongan dan Palelleng, 2013).

Tabel 3. Nilai komponen ragam dan nilai duga heritabilitas karakter agronomi dari $\mathrm{DH}_{0}$ padi beras merah

\begin{tabular}{|c|c|c|c|c|c|c|c|}
\hline Karakter & $\sigma_{G}^{2}$ & $\sigma_{E}^{2}$ & $\sigma_{P}^{2}$ & $\mathrm{KKG}$ & KKP & $\mathrm{h}_{\mathrm{bs}}^{2}(\%)$ & Kriteria \\
\hline TT & 43.1 & 69.2 & 66.1 & 5.4 & 6.6 & 65.1 & Tinggi \\
\hline JAP & 11.2 & 34.8 & 22.8 & 15.2 & 21.7 & 49.1 & Sedang \\
\hline UPAN & 18.1 & 10.4 & 21.5 & 3.7 & 4.0 & 83.9 & Tinggi \\
\hline PM & 6.5 & 3.4 & 7.7 & 11.3 & 12.2 & 85.2 & Tinggi \\
\hline JGM & $1,054.7$ & 781.8 & $1,315.3$ & 23.9 & 26.7 & 80.2 & Tinggi \\
\hline JGIM & 523.8 & 960.4 & 843.9 & 21.9 & 27.8 & 62.1 & Tinggi \\
\hline JGHM & 0.0 & 0.1 & 0.1 & 0.6 & 0.8 & 51.8 & Sedang \\
\hline B100 & 1.1 & 4.6 & 2.6 & 5.7 & 8.8 & 41.9 & Sedang \\
\hline HGKR & 0.0 & 0.2 & 0.1 & 0.4 & 0.9 & 16.4 & Rendah \\
\hline
\end{tabular}

Keterangan: $\sigma_{G}^{2}=$ ragam genotipe, $\sigma_{E}^{2}=$ ragam lingkungan, $\sigma_{P}^{2}=$ ragam fenotipe, $\mathrm{KKG}=$ koefisien keragaman genetik, $\mathrm{KKP}=$ koefisien keragaman fenotipe, $\sigma\left(\mathrm{h}^{2} \mathrm{bs}\right)=$ standar deviasi heritabilitas, $\mathrm{H}^{2} \mathrm{bs}=$ heritabilitas arti luas, TT = tinggi tanaman, JAP = jumlah anakan produktif, UPAN = umur panen, $\mathrm{PM}=$ panjang malai, JGM = jumlah gabah per malai, JGIM = jumlah gabah isi per malai, JGHM = jumlah gabah hampa per malai, B100 = Bobot 100 butir, HGKR = hasil gabah kering per rumpun

\section{KESIMPULAN}

Terdapat keragaman karakter antar $\mathrm{DH}_{0}$ padi beras merah hasil kultur antera yang diuji. Beberapa galur menunjukkan karakter yang lebih unggul dari varietas pembandingnya, yaitu umur panen nyata lebih genjah dibanding Aek Sibundong dan Inpari 24 dicapai oleh galur MW4-62-2-2. Gabah isi nyata lebih banyak dibanding Aek Sibundong dicapai oleh galur MW2-2-2-1, MW2-7-1-1, MW2-7-1-2, dan MW3-9-2-1. Sebanyak 30 galur beras merah berpotensi untuk diseleksi karena memiliki hasil gabah kering per rumpun lebih dari $25 \mathrm{~g}$. Karakter tinggi tanaman, umur panen, panjang malai, jumlah gabah per malai, dan jumlah gabah isi per malai dapat digunakan sebagai acuan seleksi yang efektif untuk memperoleh padi beras merah unggul berproduksi tinggi.

\section{DAFTAR PUSTAKA}

Aryana, G.P.M. 2009. Adaptasi dan stabilitas hasil galurgalur padi beras merah pada tiga lingkungan tumbuh. J. Agron. Indonesia. 37:95-100.

[BB Padi] Balai Besar Penelitian Tanaman Padi. 2018. Klasifikasi umur padi. http://bbpadi. litbang. pertanian.go.id [6 Agustus 2018].

Dewi, I.S., A.C. Trilaksana, B.S. Purwoko, Trikoesoemaningtyas. 2009. Karakterisasi galur haploid ganda hasil kultur antera padi. Bul. Plasma Nutfah 15:1-12. 
Dewi, I.S., B.S. Purwoko. 2012. Kultur antera untuk percepatan perakitan varietas padi di Indonesia. J. AgroBiogen. 8:78-88.

Dewi, I.S., E.G. Lestari, Chaerani, R. Yunita. 2015. Penampilan galur harapan mutan dihaploid padi tipe baru di Sulawesi Selatan. J. Agron. Indonesia 43:8998.

Diptaningsari, D. 2013.Analisis keragaan karakteragronomis dan stabilitas galur harapan padi gogo turunan padi lokal Pulau Buru hasil kultur antera. Tesis. Sekolah Pascasarjana. Institut Pertanian Bogor.

Djoar, D.W., M. Molo, E. Widiyanti, N. Setyowati, D. Mursito. 2013. Pemuliaan Padi Beras Merah Berbasis Farmer Friendly Technology dalam Rangka Peningkatan Ketahanan Pangan Masyarakat Petani Lahan Kering di Kabupaten Wonogiri. Surakarta: LPPM UNS.

Hairmansis, A., B. Kustianto, Supartopo, Suwarno. 2010. Correlation analysis of agronomic characters and grain yield of rice for tidal swamp areas. Indonesian J. Agric. Sci. 11:11-15.

Handayani, T., I.M. Hidayat. 2012. Keragaman genetik dan heritabilitas beberapa karakter utama pada kedelai sayur dan implikasinya untuk seleksi perbaikan produksi. J. Hort. 22:327-333.

Herawati, R., B.S. Purwoko, I.S. Dewi. 2009. Keragaman genetik dan karakter agronomi galur haploid ganda padi gogo dengan sifat-sifat tipe baru hasil kultur antera. J. Agron. Indonesia 37:87-94.

Herawati,R.,B.S.Purwoko,I.S.Dewi.2010.Characterization of doubled haploid derived from anther culture for new plant type upland rice. J. Agron. Indonesia 38:117-184.

Indrasari, S.D. 2011. Pengaruh penyosohan gabah dan pemasakan terhadap kandungan vitamin $\mathrm{B}$ beras merah. J. Penelitian Pertanian Tanaman Pangan 30:182-188.

Indrasari, S.D., P. Wibowo, E.Y. Purwani. 2010. Evaluasi mutu fisik, mutu giling, dan kandungan antosianin kultivar beras merah. J. Penelitian Pertanian Tanaman Pangan 29:56-62.

Kristamtini, Sutarno, E.W. Wiranti, S. Widyayanti. 2016. Kemajuan genetik dan heritabilitas karakter agronomi padi beras hitam pada populasi F2. J. Penelitian Pertanian Tanaman Pangan 35:119-124.
Limbongan, Y.L., S. Palelleng. 2013. Efektivitas seleksi generasi F2 hasil persilangan padi unggul lokal Toraja dengan padi tipe baru Inpari 7. J.AgroSainT. 5:1-10.

Mishra, R., G.J.N. Rao, R.N. Rao, P. Kaushal. 2015. Development and characterization of elite doubledhaploid lines from two indica rice hybrids. Rice Sci. 22:290-299.

Mohamed, S.M., E.E. Ali, T.Y. Mohamed. 2012. Study of heritability and genetic variability among different plant and fruit characters of tomato (Solanum lycopersicon L.). J. Sci. Technol. Res. 1:55-58.

Purbokurniawan, B.S. Purwoko, D. Wirnas, I.S. Dewi. 2014. Potensi dan stabilitas hasil, serta adaptabilitas galur-galur padi gogo tipe baru hasil kultur antera. J. Agron. Indonesia 42:9-16.

Rusdiansyah, Y.I. Intara. 2015. Identifikasi kultivar lokal padi sawah (Oryza sativa L.) Kalimantan Timur berdasarkan karakter agronomi dan morfologi. J. Agrovigor 8:8-15.

Santika, A., Rozakurniati. 2010. Teknik evaluasi mutu beras dan beras merah pada beberapa galur padi gogo. Bul. Teknik Pertanian 15:1-5.

Selvaraj, I.C., P. Nagarajan, K. Thiyagarajan, M. Bharathi, R. Rabindran. 2011. Genetic parameters of variability, correlation, and path coefficient studies for grain yield and other yield attributes among rice blast disease resistant genotypes of rice (Oryza sativa L.). Afr. J. Biotechnol. 10:3323-3334.

Silitonga, T.S., I.H. Somantri, A.A. Daradjat, H. Kurniawan. 2003. Panduan Sistem Karakterisasi dan Evaluasi Tanaman Padi. Komisi Nasional Plasma Nutfah. Bogor.

Sitaresmi, T., H. Rina, Wening, T. Ami, Rakhmi, N. Yunani, U. Susanto. 2013. Pemanfaatan plasma nutfah padi varietas lokal dalam perakitan varietas unggul. Iptek Tanaman Pangan 8:22-30.

Stansfield, W.D. 1983. Theory and Problems of Genetics. Edisi ke-2. Schaum's Outline Series. McGraw-Hill Book Company. New Delhi, INA.

Zhengjin, X.U., C. Wenfu, Z. Longbu, Y. Shouren. 2005. Design principles and parameters of rice ideal panicle type. Chinese Sci. Bull. 50:2253-2256. 